\title{
Amine-modified silica for removing aspirin from water
}

\author{
A. F. Danil de Namor ${ }^{1}$ (D) M. Al Nuaim² ${ }^{2}$ G. Fairclough ${ }^{1} \cdot$ R. Khalife ${ }^{3} \cdot$ N. Al Hakawati ${ }^{4}$
}

Received: 13 February 2020 / Revised: 28 March 2021 / Accepted: 24 May 2021 / Published online: 7 June 2021

(c) Crown 2021

\begin{abstract}
The synthesis and structural characterisation (Fourier transform infrared, FTIR spectrometry, scanning electron microscopy, SEM and energy-dispersive X-ray, EDX) of amino-modified silicates (unloaded L1, and aspirin-loaded, L2) are reported. The optimal conditions for the extraction of aspirin from water by the modified silicate material were determined as a function of the mass of the extracting agent and the $\mathrm{pH}$ of the aqueous solution. The optimum mass was found to be $0.08-0.10 \mathrm{~g}$ with 99.9\% removal of aspirin. Maximum extraction of aspirin by the material was observed at $\mathrm{pH} 4$. The kinetics, the removal capacity of the material, as well as its recycling, were investigated. The results indicate that (i) the process is fast and (ii) the removal capacity for the drug is greater than that of previously reported materials and (iii)the modified silicate can be easily recycled. These data along with the low cost involved in the production of the material led to the conclusion that the modified silicate has the required potential for industrial use. Molecular simulation calculations suggest that one unit of aspirin interacts with one unit of the modified silicate L1 through hydrogen bond formation between the amine functional group of the silicate and the oxygen donor atoms of aspirin. Final conclusions are given.
\end{abstract}

Keywords Aspirin $\cdot$ Amino silicates $\cdot$ Extraction $\cdot$ Capacity $\cdot$ Kinetics

\section{Introduction}

Contamination of drinking water by pharmaceuticals is a topic which has gained considerable interest in recent years. The importance of this research area has been emphasised in the report published by the World Health Organization (WHO) in 2012 which addressed several issues such as the presence of pharmaceuticals in water, their risk to human health, a variety of technological approaches for their removal, as well as prevention methods concluding remarks and recommendations were given. (WHO 2012).

Editorial responsibility: Samareh Mirkia.

A. F. Danil de Namor

a.danil-de-namor@surrey.ac.uk

1 Laboratory of Thermochemistry, Department of Chemistry, University of Surrey, Guildford GU2 7XH, Surrey, UK

2 Department of Pharmaceutical Chemistry, College of Pharmacy, University of Basrah, Basrah, Iraq

3 School of Chemical, Biological and Environmental Engineering, Oregon State University, Corvallis, OR 97331, USA

4 Department of Biological Sciences, Faculty of Science, Beirut Arab University, Debbieh 1107-2809, Lebanon
An important aspect to consider is that regarding the development of innovative technologies for their removal. Aspirin (acetyl salicylic acid) (Fig. 1) is one of the analgesics most frequently used for reducing pain, inflammation, heart attacks prevention, angina and strokes (Albert 2010; Mundasad 2016). However, its excessive use has led to a high degree of water contamination from point and non-point sources (Nicolaou et al. 2007). Recently, a number of studies have reported the use of different approaches for the removal of aspirin from water. Such approaches included photocatalysis using titanium dioxide ( $\mathrm{Li}$ et al. 2018), graphene nanoplatelets (Al-Khateeb et al. 2014), electrocoagulation (Ozyonar and Aksoy 2016), and membrane separation technology (Khamis et al. 2011).

Several research groups have used mesoporous silica for removing pharmaceuticals including aspirin from water (Bui and Choi 2009; Punyapalakul and Sitthisorn 2010; Kim et al. 2014; Akhtar et al. 2016).

In an attempt to explore the field of supramolecular chemistry, Danil de Namor et al. (2017) reported the selective interaction of a calix [4]arene derivative, 5,11,17,23-tetratert-butyl, 25,27-bis[amino ethoxy]26,28-dihydroxycalix[4] arene with clofibric acid, diclofenac and aspirin. It was demonstrated that the calix[4]-based receptor is a suitable 


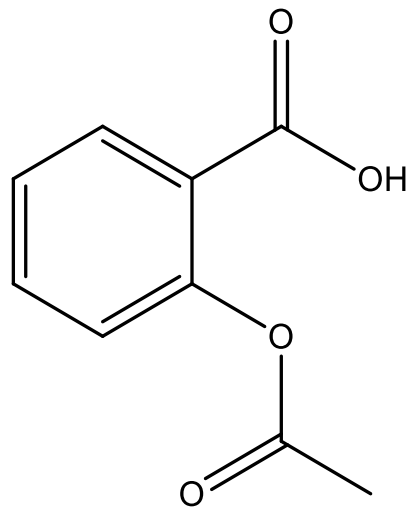

Fig. 1 Chemical structure of aspirin

extracting agent for the two former drugs but its extracting ability for aspirin was found to be very weak. Indeed the thermodynamic characterisation of these systems gave a quantitative assessment not only of the selective recognition of the calix [4]-based receptor for clofibric acid and diclofenacb but also about its hosting ability for these drugs (two drug units per unit of receptor) while a 1:1 (drug: receptor) interaction was found for aspirin. Therefore, it was thought that for technological purposes, silica is a naturally occurring material of suitable strength and structure which can be easily modified by the introduction amino functionalities, in its structure as to produce a potential material for the removal of aspirin from water. This paper reports (i) the synthesis and characterisation of modified silicate materials L1 and L2, (ii) FTIR, SEM and EDX of the unloaded and aspirin-loaded modified silicates (iii) the optimal conditions for the removal process (iv) the advantages of the modified silicate relative to previously reported material for removing aspirin from water are discussed.

\section{Materials and methods}

\section{Materials}

Silica (0.2-0.5 mm), 3-aminopropyltrimethoxysilane (97\%), 2-diethylamino ethyl chloride hydrochloride $(99.5 \%)$ and aspirin were all purchased from Aldrich Chemical Co. Aspirin (99\%) was purchased from Sigma Aldrich.

Methanol (HPLC), dried toluene, hydrochloric acid, Ethanol (HPLC), chloroform, ammonium hydroxide, triethylamine and formaldehyde (37\%) were purchased from Fisher.

\section{Preparation of modified silicate compounds}

This experiment involved the preparation of two modified silicates which would be used to capture and extract acetylsalicylic acid in aqueous solution.

\section{Synthesis of modified silicate, L1 (Ho et al. 2003)}

Silica (0.2-0.5 mm size) was activated overnight in an oven at $400^{\circ} \mathrm{C}$ and then cooled down to room temperature. The activated silica was suspended in freshly refluxed toluene $\left(150 \mathrm{~cm}^{3}\right)$ after which 3-aminopropyltrimethoxysilane (APTMS) $\left(10 \mathrm{~cm}^{3}, 54.30 \mathrm{mmol}\right)$ was added. The mixture was refluxed with vigorous stirring under a nitrogen atmosphere for $48 \mathrm{~h}$. The mixture was then cooled to room temperature, filtered and washed with methanol and toluene. The product was dried in a piston dryer at $110{ }^{\circ} \mathrm{C}$ for $20 \mathrm{~h}$. Microanalysis was carried out at the University of Surrey for L1: Found \%: C, 7.83; H, 1.95; N, 2.09. The synthetic procedure is shown in Scheme 1. (Ho et al. 2003).

\section{Attachment of diethylamine to the silicate, $\mathrm{L} 2$ (Blasius et al. 1980)}

The 2-(diethylamino) ethyl chloride hydrochloride (2.2833 $\mathrm{g}, 15 \mathrm{mmol}$ ) was placed in a $250 \mathrm{~cm}^{3}$ round bottom flask and a mixture of ethanol and chloroform $\left(100 \mathrm{~cm}^{3}: 100 \mathrm{~cm}^{3}\right)$ was added, followed by triethylamine $\left(2.1 \mathrm{~cm}^{3}, 15 \mathrm{mmol}\right)$ and formaldehyde $\left(2.4 \mathrm{~cm}^{3}, 30 \mathrm{mmol}\right)$. The mixture was stirred for one hour followed by addition of modified silica $(5 \mathrm{~g})$. This mixture was refluxed for 24 hours at $60-70{ }^{\circ} \mathrm{C}$. Then, it was cooled down and filtered to collect the solid. The resulting compound was then washed with a mixture of ethanol and chloroform and then dried overnight in a piston dryer. Scheme 2 shows the synthetic procedure to produce the modified silicate, $\mathrm{L} 2$.<smiles></smiles><smiles>C#[Si]O[Si](CCCN)(OC)OC</smiles>

Scheme 1 Synthesis of modified silicate, L1 


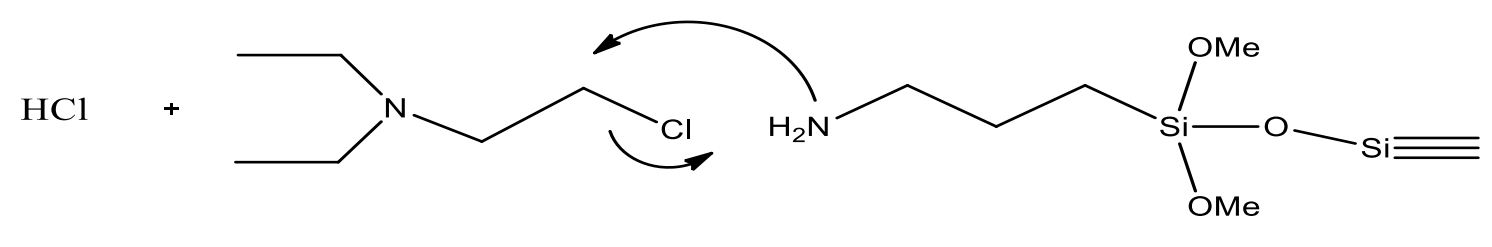

2-(diethylamino) ethyl chloride hydrochloride

Modified silicate

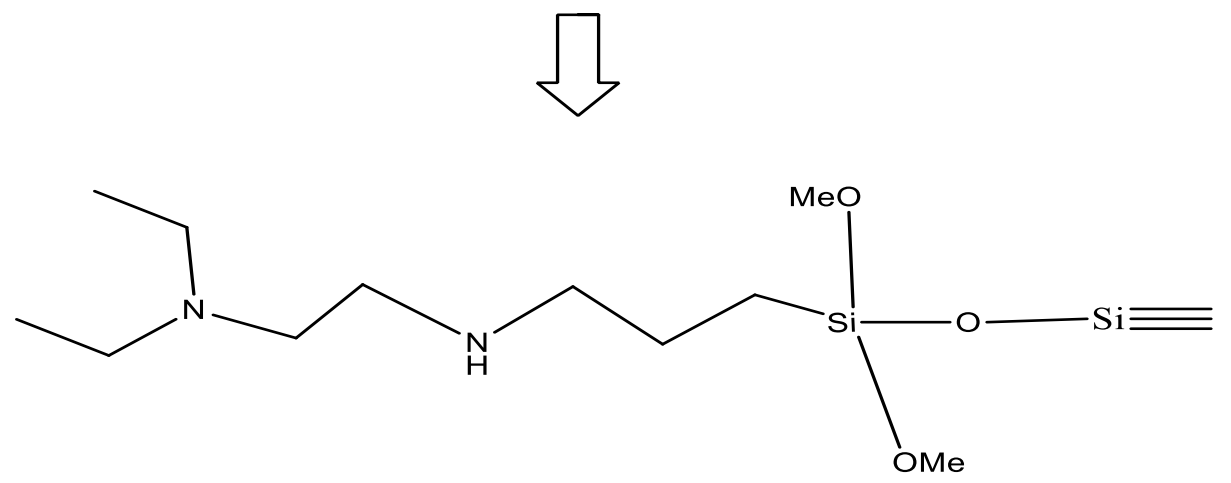

Modified Diethylamine Silicate

Scheme 2 Attachment of diethylamine group (product: N,N-Diethyl-N'-propyl-methanediamine dimethoxysilane), L2

\section{Characterisation of L1 and L2 (loaded and unloaded)}

\section{Molecular modelling}

A molecular modelling of the interaction of L1 with aspirin was carried out using Argus lab 4.0.1 software. The minimum potential energy was calculated by geometry convergence function using the software and performed according to Universal Force Field (UFF) calculation method.

\section{FTIR analysis}

The chemical surface properties of the modified silica compounds were determined by Fourier transform infrared (FTIR) spectrometry, using Agilent Cary 600 Series FTIR spectrometer. FTIR spectra were recorded by averaging 32 scans at a spectral resolution of $4 \mathrm{~cm}^{-1}$ in the wavelength region from 4000 to $600 \mathrm{~cm}^{-1}$.

\section{Scanning electron microscopy and energy-dispersive X-ray (SEM-EDX)}

A scanning electron microscope (SEM) JEOL JSM-7100F, equipped with secondary and backscattered imaging coupled with Ultradry energy-dispersive X-ray (EDX) for elemental analysis, was used for morphological investigations. L1 and L2 untreated and treated with aspirin were mounted on aluminium stub, sputtered with thin layer of gold to prevent charging of the surface. Working conditions were $15 \mathrm{keV}$ for accelerating voltage and $10 \mathrm{~mm}$ for the detector working distance.

\section{Extraction of aspirin using $\mathrm{L} 1$}

\section{Effect of the amount of L1 on the extraction of aspirin from aqueous solution}

To study the effect of the mass of the material on the uptake process, different masses of L1 (0.01-0.2 g) were added to a fixed concentration of aspirin in water $\left(5.59 \times 10^{-3} \mathrm{~mol}\right.$. $\mathrm{dm}^{-3}$ ) The mixtures were mixed well by whirlimixer and left overnight in a water bath at $298 \mathrm{~K}$. Each solution was filtered and filtrates were analysed by UV-Vis measurements where the used $\lambda \max$ for the aspirin was $276 \mathrm{~nm}$. The percentage of extraction, $\% \mathrm{E}$, is calculated according to Eq. 1.

$\% E=\frac{C_{\mathrm{i}}-C_{\mathrm{e}}}{C_{\mathrm{i}}} \times 100$

In this equation, $c_{\mathrm{i}}$ and $c_{\mathrm{e}}$ are the initial and equilibrium concentrations of aspirin before and after extraction, respectively, in mol.dm ${ }^{-3}$. 


\section{Effect of pH on the uptake of aspirin at $298 \mathrm{~K}$}

The effect of $\mathrm{pH}$ on the extraction of aspirin by $\mathrm{L} 1$ was tested by using a fixed amount of the material $(0.08 \mathrm{~g})$ and a volume $\left(10 \mathrm{~cm}^{3}\right)$ of an aqueous solution of aspirin $\left(5.59 \times 10^{-3} \mathrm{~mol}\right.$. $\mathrm{dm}^{-3}$ ) in the $2-12 \mathrm{pH}$ range. The desired $\mathrm{pH}$ of the solution was attainable by adding hydrochloric acid $(\mathrm{HCl})$ or ammonium hydroxide $\left(\mathrm{NH}_{4} \mathrm{OH}\right)$ solution. Buffer solutions of $\mathrm{pH} 4$ and 9.2 were used for calibration. The percentage of extraction, $\% \mathrm{E}$, is calculated using Eq. 1.

\section{Kinetics of removal of aspirin from aqueous solution at $298 \mathrm{~K}$}

In order to assess the kinetics of the removal processes, separate fixed amounts of $\mathrm{L} 1(0.08 \mathrm{~g})$ were mixed with aqueous solutions of aspirin $\left(5.59 \times 10^{-3} \mathrm{~mol} \mathrm{dm}^{-3}\right)$ at different contact times ranging from 15 to $1080 \mathrm{~min}$ at $298 \mathrm{~K}$, while other parameters such as $\mathrm{pH}(\sim 4)$, temperature $(298 \mathrm{~K})$ were kept constant.

\section{Determination of the uptake capacity of the materials}

Batch experiments were carried out at $298 \mathrm{~K}$ by varying the concentrations of aspirin $\left(1.00 \times 10^{-3}-1.00 \times 10^{-2} \mathrm{~mol} \mathrm{dm}^{-3}\right)$ with a fixed mass of the material $(0.08 \mathrm{~g})$ in order to determine the capacity of the material to extract aspirin from aqueous solution.

The capacity $\mathrm{q}\left(\mathrm{mmol} \mathrm{g}^{-1}\right)$ amount of aspirin taken up per unit of mass of material is calculated from Eq. 2 .

$q=\frac{(C i-C e) V}{m}$

In Eq. 2, $c_{\mathrm{i}}$ and $c_{\mathrm{e}}$ are the initial and equilibrium concentrations of aspirin before and after extraction, respectively, in mol. $\mathrm{dm}^{-3}, m$ is the mass of the material used in gram $(\mathrm{g})$ and $V$ is the volume of the solution in $\mathrm{dm}^{3}$.

Extraction experiments of aspirin in aqueous solutions using batch approach were carried out in duplicate and average values are reported.

\section{Recycling of the loaded silicate}

The material was recycled by a $\mathrm{pH}$ switching mechanism using $\mathrm{HCl} 0.1 \mathrm{M}$. The modified silicate loaded with aspirin ( $5 \mathrm{~g})$ was placed in a column and treated with an aqueous solution of $\mathrm{HCl} 0.1 \mathrm{M}$ until the amount of aspirin in the effluent was undetectable. Then, the material was washed with deionised water and dried in an oven at $110^{\circ} \mathrm{C}$ and its capacity was determined. This operation was repeated ten times.

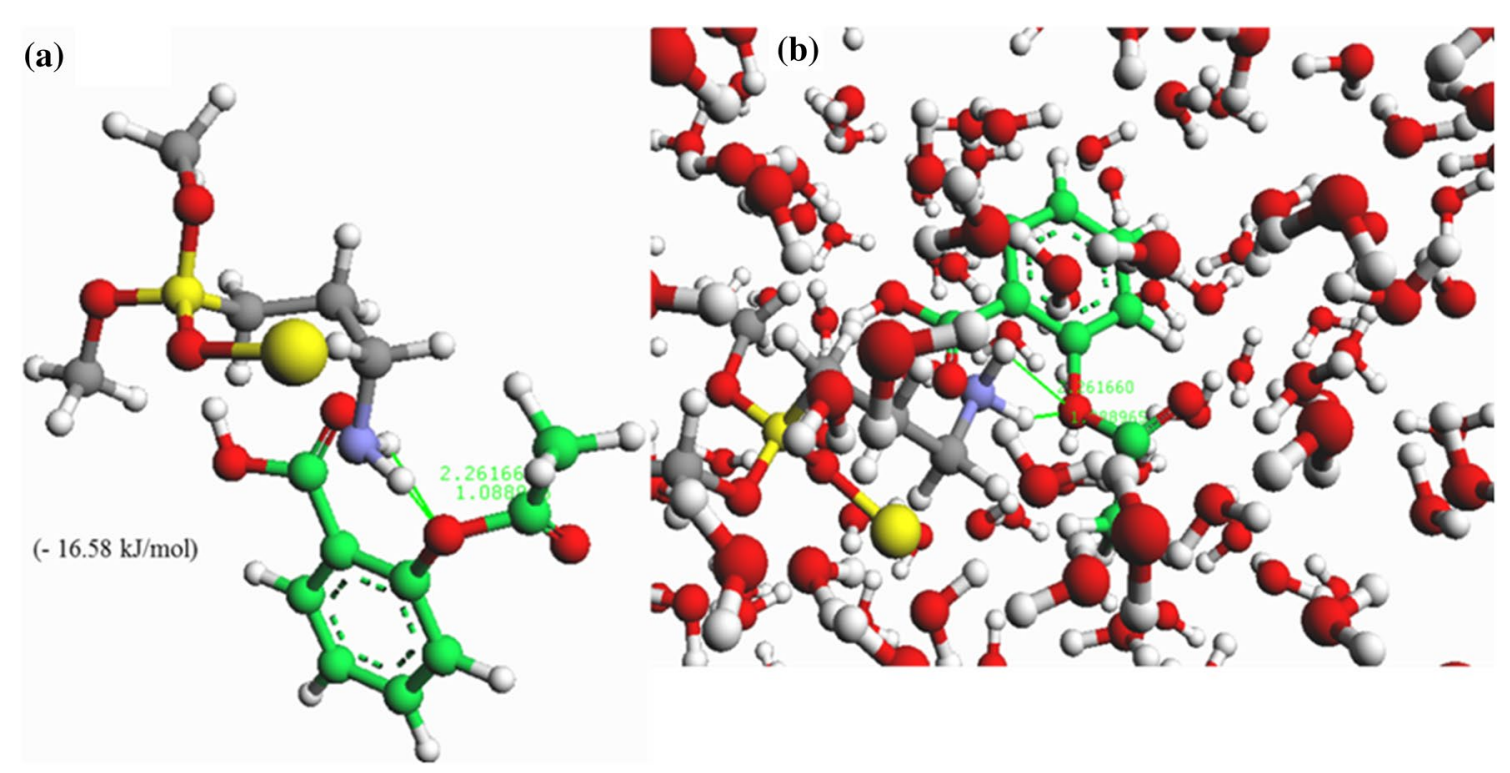

Fig. 2 Molecular simulation for the interaction of L1 with aspirin and its computed interaction energy (a). Hydrogen bonds designated by green lines 


\section{Results and discussion}

\section{Molecular modelling}

The interaction of aspirin was simulated using $\mathrm{L} 1$ as a representative example. The aim was to gain suggestions regarding the forces involved in the interaction of the modified silicate and aspirin. Figure 2a, b shows a subtle stability detected through the $\mathrm{H}$-bond formation between the $-\mathrm{NH}$ functional group of L1 and the oxygen donor atom of aspirin which indicate a 1:1 binding mode. From the energetic perspective, aspirin-modified silicate interaction is enthalpically stable $\left(-16.58 \mathrm{~kJ} \cdot \mathrm{mol}^{-1}\right)$. These suggestions were corroborated by FTIR analysis as discussed below.

\section{FTIR analysis}

FTIR spectroscopy analysis was carried out for L1 and L2 (unloaded and aspirin-loaded materials) as shown in Fig. 3a, $b$, respectively.
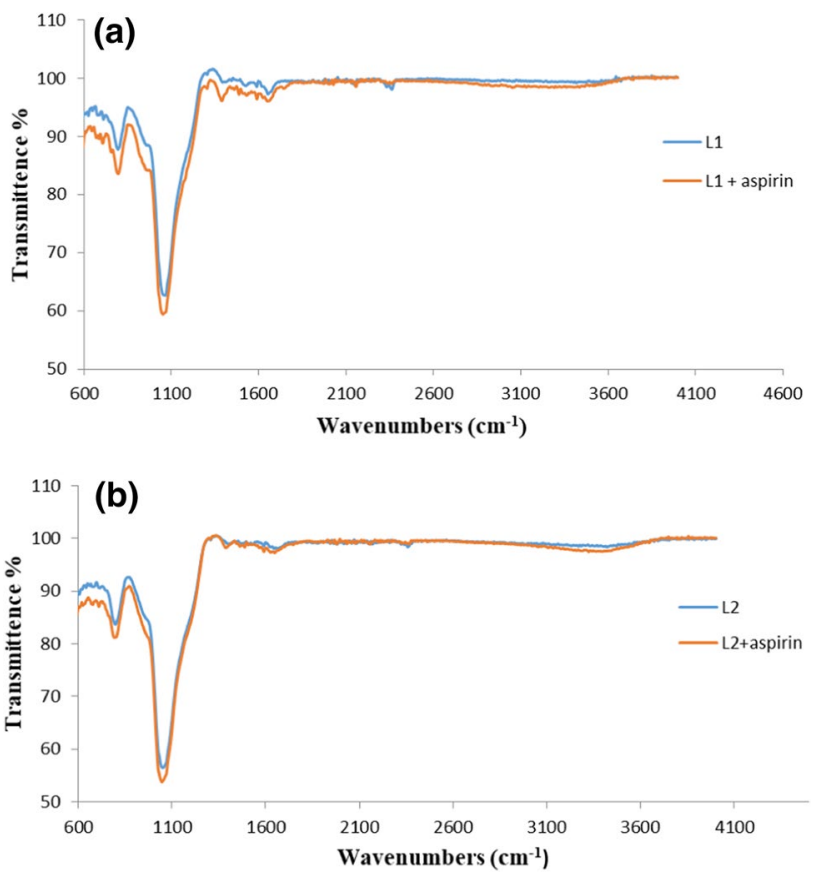

Fig. 3 FTIR spectra of unloaded and aspirin-loaded L1 and L2 materials
For the unloaded material, strong and sharp bands observed in Fig. 3a correspond to $\mathrm{Si}-\mathrm{O}-\mathrm{Si}\left(1040 \mathrm{~cm}^{-1}\right)$, Si-O $\left(800 \mathrm{~cm}^{-1}\right)$ and $\mathrm{N}-\mathrm{H}\left(1640 \mathrm{~cm}^{-1}\right)$ (Parida et al. 2006; Hernandez-Morales et al. 2012). The peak at $980 \mathrm{~cm}^{-1}$ is attributed to $\mathrm{Si}-\mathrm{OH}$ bond stretching and the stretching and bending vibrations of the amino propyl functionality (Zhang et al. 2008). The presence of $\mathrm{CH}_{2}$ is reflected by the peak observed at $1380 \mathrm{~cm}^{-1}$.

The shift observed in the $\mathrm{NH}$ peaks of the loaded material shown in Fig. 3a indicates the involvement of this functional group on the uptake of aspirin which is in accord with the suggestion given in the molecular modelling. The slight shifts observed in the $\mathrm{Si}-\mathrm{O}-\mathrm{Si}$ and $\mathrm{Si}-\mathrm{O}$ peaks are attributed to the configurational rearrangement of $\mathrm{L} 1$ upon interaction with aspirin.

Figure 3 b shows similar peaks positions for $\mathrm{L} 2$ functional groups. However, in the presence of aspirin, no significant shifts were observed

\section{Analysis of L1 and L2 unloaded and aspirin loaded by SEM-EDX}

The morphology and the surface of L1 and L2 materials untreated and treated with aspirin were analysed using the SEM-EDX technique where micrographs and spectra are presented in Fig. 4. L1 and L2 morphologies (Fig. 4a, c) appear to consist of macro-particles with smooth large surfaces. The morphology of both materials does not seem to be altered by the presence of aspirin. However, an increase in the level of carbon and oxygen peaks in the EDX spectra (Fig. 4b, d) is observed suggesting the presence of aspirin in the materials. Moreover, smaller, white patches were observed on L1 and L2 micrographs indicating the uptake of aspirin by the investigated materials.

The outcome of the IR and SEM-EDX is indicative that the interaction of L1 with aspirin is stronger than that for L2. This is an unexpected result given that the tertiary amine is more basic the primary amine. This must be attributed to the fact that the primary amine in L1 is more available to interact with the drug than the tertiary amine in L2. Therefore, L1 was the material selected for investigating its use as extracting agent for the removal of aspirin from aqueous medium.

\section{Removal of aspirin from water using modified silicates}

Many factors need to be considered in the removal of pollutants from water. Among them, the mass of material, the $\mathrm{pH}$ of the aqueous solution, the kinetics of the process and the 

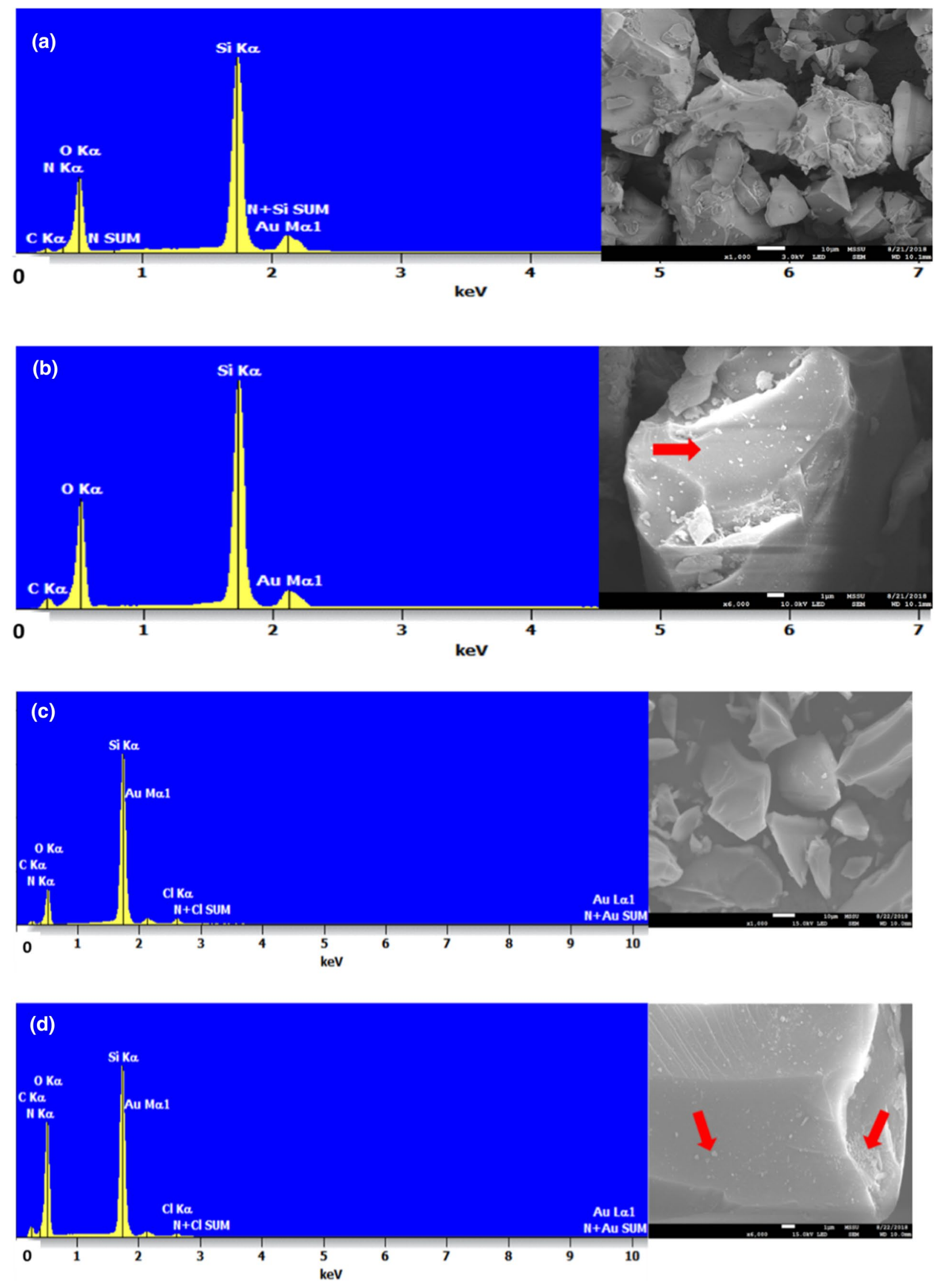
4Fig. 4 SEM images and EDX spectra showing the microstructures and the elemental composition of L1 (a); L1 treated with aspirin (b); L2 (c) and L2 treated with aspirin (d). Au peak referred to the gold coating of the samples

removal capacity of the material for the targeted pollutant were investigated with the aim of establishing the optimum conditions for removing aspirin from water by L1. In addition for commercial purposes recycling of the material, a key parameter was considered.

\section{Determination of optimum amount of L1 for the uptake of aspirin from water at $298 \mathrm{~K}$}

Figure 5 shows that as the amount of L1 increases, the extraction percentage (\% E) increases until saturation occurs and this is due to the increase in the sites of interaction (amino active sites) in the material. It is concluded that the optimum mass to be used for almost complete removal of aspirin from water by $\mathrm{L} 1$ is between 0.08 to $0.10 \mathrm{~g}$.

\section{Effect of $\mathrm{pH}$ of the aqueous solution on the removal of aspirin by $L 1$ at $298 \mathrm{~K}$}

Figure 6 shows the effect of varying the $\mathrm{pH}$ of the aqueous solution of aspirin against the \% $\mathrm{E}$. At $\mathrm{pH}$ lower than the $\mathrm{pKa}$ of aspirin, the undissociated drug predominates in aqueous solution. At $\mathrm{pH}=3.5$, the concentrations of the undissociated and dissociated drug are the same. At $\mathrm{pH}$ higher than 3.5, the dissociated species predominates in solution. The results shown in Fig. 6 clearly indicate that hardly any extraction of the pharmaceutical takes place at low $\mathrm{pH}$. This is due to the protonation of the amino group in L1 which limits the availability of the binding sites of the material. As the $\mathrm{pH}$ increases and ionic species predominate in aqueous medium, the percentage of aspirin removed by the modified silicate increases until the material is fully saturated and no further changes are observed. Another outcome of this investigation is the fact that at lower $\mathrm{pH}$, there is hardly any extraction of aspirin. This finding led us to explore the possibility of recycling the material via a $\mathrm{pH}$ switching mechanism as described in the final part of this paper.

\section{Kinetics of removal of aspirin by $L 1$}

The purpose of this experiment is to assess the kinetics of the extraction process which is an important aspect to be considered for industrial use. The experimental data for L1 were fitted to a simple exponential model assuming that the rate of the uptake of the materials is proportional to the distance from equilibrium (i.e. pseudo-first-order process).
Figure 7 shows that the obtained rate of equilibrium (k) for aspirin removal was found to be 0.05 with half-life of $14 \mathrm{~min}$ for L1. It is therefore concluded that the kinetics of the process is fast.

\section{Determination of the capacity of L1 for the removal of aspirin from water at $298 \mathrm{~K}$ Comparison with other materials previously reported}

The uptake in mmol. $\mathrm{g}^{-1}$ of L1 against the molar concentration of aspirin is shown in Fig. 8. The results show that the capacity of L1 to remove aspirin from aqueous solution is $1.27 \mathrm{mmol} \mathrm{g}^{-1}\left(228.79 \mathrm{mg} . \mathrm{g}^{-1}\right)$. The results are striking and indicate that $\mathrm{L} 1$ is an efficient material for the removal of aspirin from water to an extent that its capacity to remove this drug from water is much higher than those capacities of materials previously reported as shown in Table 1 including those reported by Mphahlele and co-workers (Mphahlele et al. 2015). The materials consisted of polymerised nanotubes containing nitrogen and cyclodextrin (N-NT- CD) and iron (Fe/N-NT-CD). The results showed that the capacities of the materials to extract aspirin were 71.9 and $101 \mathrm{mg}$. $\mathrm{g}^{-1}$, respectively (Mphahlele et al. 2015). An additional advantage of $\mathrm{L} 1$ relative to the latter is the reduction of steps required to synthesise the material and the consequent reduction in cost and time. Graphene nanoplatelets were also used for the extraction of aspirin by Al-Khateeb and co-workers (Al-Khateeb 2014) and a capacity of only $12.98 \mathrm{mg} . \mathrm{g}^{-1}$ was found (Datt et al. 2012). The results show that the capacity of $\mathrm{L} 1$ is greater by factors of 2.54, 3.01, 4.22, 3.75 and $3.87 \mathrm{mg} . \mathrm{g}^{-1}$ relative to MS, MS-CC-1, MS-CC-2, MS-PS-1 and MS-PS-2, respectively. These data demonstrate again that the silica-based material reported in this paper is characterised by a much higher removal capacity and lower cost (18 US dollars per $10 \mathrm{~g}$ of L1) than those silica-based compounds reported in the literature (Datt et al. 2012). In addition to the number of steps, time consumption and chemicals needed for its preparation are significantly reduced.

\section{Recycling of L1}

Figure 9 is a plot of the removal capacity of the material after recycling the material ten times using $0.1 \mathrm{~mol} . \mathrm{dm}^{-3}$ $\mathrm{HCl}$ a reduction of $18.6 \%(53.71 \mathrm{mg} / \mathrm{g})$ in its capacity is observed which means that still after this number of recycles, this material has a much higher capacity $(175.09 \mathrm{mg} / \mathrm{g})$ than existing ones. It is quite clear from these preliminary studies that there is a scope for further recycling processes before reaching the capacity of the unrecycled materials reported in the literature. 


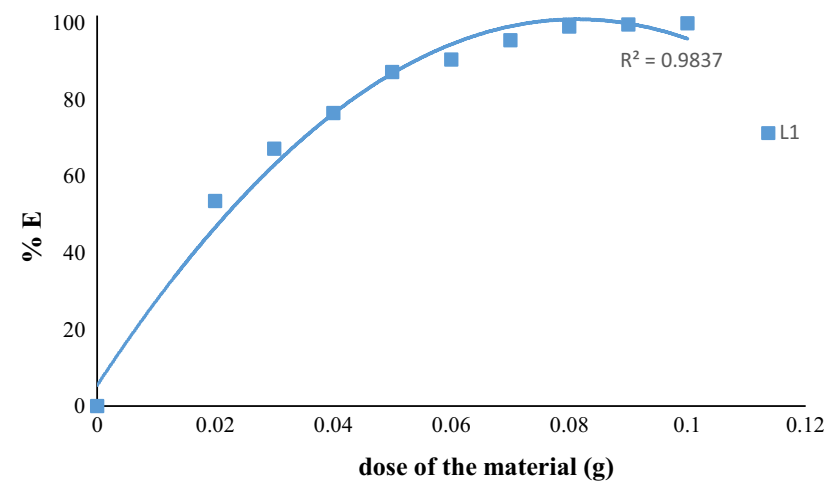

Fig. 5 Effect of masses on the uptake of aspirin from aqueous solution by the $\mathrm{L} 1$ at $298 \mathrm{~K}, \mathrm{C}_{\mathrm{i}}=5.59 \times 10^{-3} \mathrm{~mol} \mathrm{dm}^{-3}, \mathrm{~V}=10 \mathrm{~cm}^{3}$ at $298 \mathrm{~K}$

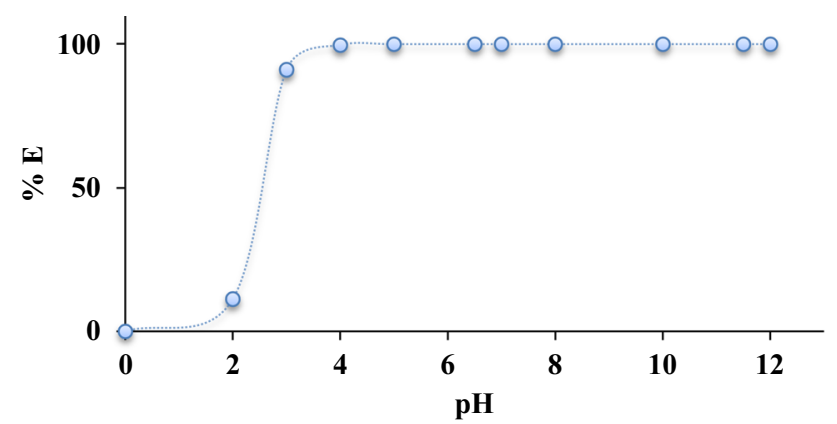

Fig. 6 Effect of $\mathrm{pH}$ of the aqueous solution on the removal of aspirin from water $\left(5.59 \times 10^{-5} \mathrm{~mol} \mathrm{dm}^{-3}, 10 \mathrm{~cm}^{3}\right)$ by L1 at $298 \mathrm{~K}$

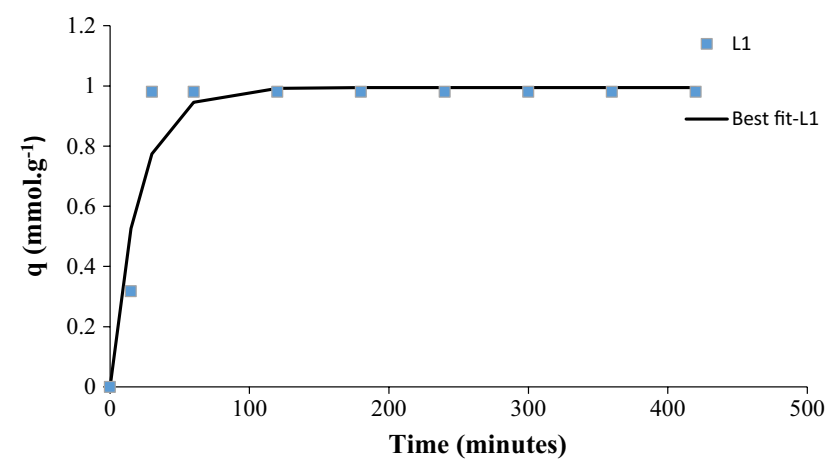

Fig. 7 Determination of the optimum time for the uptake of aspirin by $\mathrm{L} 1$ from aqueous solution at $298 \mathrm{~K}$

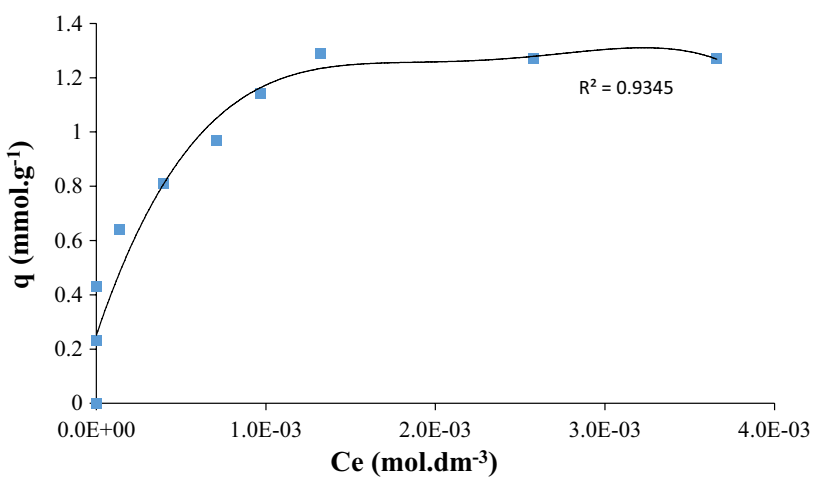

Fig. 8 Uptake capacity $\left(\mathrm{mmol} . \mathrm{g}^{-1}\right)$ of $\mathrm{L} 1$ to remove aspirin from aqueous solution at $298 \mathrm{~K}$

\section{Conclusion}

From the above discussion, the following conclusions are drawn:

(i) This paper shows the importance of enriching naturally occurring materials for the development of low-cost methodologies for the removal of pharmaceuticals from water, particularly those which are frequently used and therefore most likely to contaminate water.

(ii) The suggestions given from molecular simulation calculations regarding the possible sites of interactions between the species involved are corroborated by experimental data.

(iii) The need to determine experimentally the capacity of the material to remove the targeted drug in order to proceed with comparative studies with existing ones. This information is not often reported. It was found that the capacity of $\mathrm{L} 1$ to remove aspirin from aqueous solution is $1.27 \mathrm{mmol} \mathrm{g}^{-1}\left(228.79 \mathrm{mg} \mathrm{g}^{-1}\right)$. This material has a higher capacity than existing ones and can be easily recycled by treatment with $\mathrm{HCl} 0.1$ M.

(iv) The relevance of assessing the $\mathrm{pH}$ effect of the aqueous solution on the extraction process is not only to optimise the process but also for exploring the possibility of recycling the material via a pH switching mechanism. The optimum $\mathrm{pH}$ for highest removal of aspirin from water by the modified silica was found to be around 4 at the standard temperature of $298 \mathrm{~K}$. 
Table 1 Capacity (mg.g $\mathrm{g}^{-1}$ ) of reported materials to remove aspirin from aqueous solution relative to $\mathrm{L} 1$

\begin{tabular}{llll}
\hline Material & Capacity $\left(\mathrm{mg}^{-g^{-1}}\right)$ & Synthetic steps & References \\
\hline Graphene nanoplatelets & 12.98 & 1 step & Al-khateeb et al. (2014) \\
Clay Micelle complex & 57.47 & 1 step & Khamis et al. (2011) \\
Activated carbon adsorber & 61.73 & 1 step & Khamis et al. (2011) \\
N-NT-CD & 71.9 & 2 steps & Mphahlele et al. (2015) \\
Fe/N-NT-CD & 101.0 & 3 steps & Mphahlele et al. (2015) \\
MS & 90 & 1 step & Datt et al. (2012) \\
MS- CC-1 & 76 & 3 steps & Datt et al. (2012) \\
MS-CC-2 & 3 steps & Datt et al. (2012) \\
MS-PS-1 & 54 & 4 steps & Datt et al. (2012) \\
MS-PS-2 & 61 & 4 steps & Datt et al. (2012) \\
L1 & 59 & 1 step & This work \\
\hline
\end{tabular}

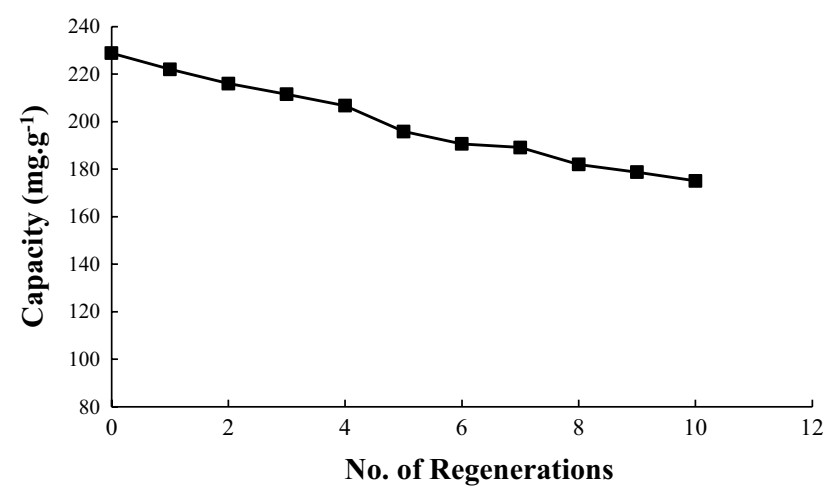

Fig. 9 Capacity of the material (mg.g $\left.{ }^{-1}\right)$ for aspirin after several recycling

Acknowledgements The authors thank Prof. John Watts and his staff for invaluable assistance in the use of the SEM equipment available in the Micro Structural Unit and Surface Analysis Laboratory (University of Surrey).

Funding This research did not receive any specific funding.

Data and material availability The data generated during this research study are available from the corresponding author upon request.

\section{Declaration}

Conflict of interest The authors declare no conflict of interest.

Open Access This article is licensed under a Creative Commons Attribution 4.0 International License, which permits use, sharing, adaptation, distribution and reproduction in any medium or format, as long as you give appropriate credit to the original author(s) and the source, provide a link to the Creative Commons licence, and indicate if changes were made. The images or other third party material in this article are included in the article's Creative Commons licence, unless indicated otherwise in a credit line to the material. If material is not included in the article's Creative Commons licence and your intended use is not permitted by statutory regulation or exceeds the permitted use, you will need to obtain permission directly from the copyright holder. To view a copy of this licence, visit http://creativecommons.org/licenses/by/4.0/.

\section{References}

Akhtar J, Amin NAS, Shahzad K (2016) A review on removal of pharmaceuticals from water by adsorption. Desalin Water Treat 57:1-19

Albert JS (2010) Lead generation approaches in drug discovery. Wiley, New Jersey

Al-Khateeb LA, Almotiry S, Abdel Salam M (2014) Adsorption of pharmaceutical pollutants onto graphene nanoplatelets. Chem Eng J 248:191-199

Blasius E, Janzen KP, Keller M, Lander H, Nguyen-Tien T, Scholtien G (1980) Austauscher mit cyclischen Polyethern als AnkergruppenII. Talanta 27:107-126

Bui TX, Choi H (2009) Adsorptive removal of selected pharmaceuticals by mesoporous silica SBA-15. J Hazard Mater 168:602-608

Danil de Namor AF, Al Nuaim M, Villanueva Salas JA, Bryant S, Howlin B (2017) A calix[4]arene derivative and its selective interaction with drugs (clofibric acid, diclofenac and aspirin). Eur J Pharm Sci 110:1-8

Datt A, El-Maazawi I, Larsen SC (2012) Aspirin Loading and Release from MCM-41 Functionalized with Aminopropyl Groups via Co-condensation or Postsynthesis Modification Methods. J Phys Chem C 116:18358-18366

Hernandez-Morales V, Nava R, Acosta-Silva YJ, Macias-Sanchez SA, Pérez-Bueno JJ, Pawelec B (2012) Adsorption of lead (II) on SBA-15 mesoporous molecular sieve functionalized with $-\mathrm{NH}_{2}$ groups. Microporous Mesoporous Mater 160:133-142

Ho KY, McKay G, Yeung KL (2003) Selective adsorbents from ordered mesoporous silica. Langmuir 19:3019-3024

Khamis M, Karaman R, Ayyash F, Qtait A, Deeb O, Manssra A (2011) Efficiency of advanced membrane wastewater treatment plant towards removal of aspirin, salicylic acid, paracetamol and p-aminophenol. J Environ Sci Eng 5:121-137

Kim Y, Bae J, Park J, Suh J, Lee S, Park H, Choi H (2014) Removal of 12 selected pharmaceuticals by granular mesoporous silica SBA15 in aqueous phase. Chem Eng J 256:475-485

Li L, Ma Q, Wang S, Song S, Li B, Guo R, Cheng X, Cheng Q (2018) Photocatalytic performance and degradation mechanism of aspirin by $\mathrm{TiO} 2$ through response surface methodology. Catalysts 8:118-166

Mphahlele K, Onyango MS, Mhlanga SD (2015) Adsorption of aspirin and paracetamol from aqueous solution using $\mathrm{Fe} / \mathrm{N}-\mathrm{CNT} / \beta$ cyclodextrin nanocomopsites synthesized via a benign microwave assisted method. J Environ Chem Eng 3:2619-2630

Mundasad S (2016) Asthma pill 'promising' for people with severe symptoms (BBC News). Available at https://www.bbc.com/news/ health-36987243. Verified 6 August 2014. 
Nicolaou A, Meric S, Fatta D (2007) Occurrence patterns of pharmaceuticals in water and wastewater environments. Anal Bioanal Chem 387:1225-1234

Ozyonar F, Aksoy S (2016) Removal of Salicylic Acid from Aqueous Solutions Using

Various Electrodes and Different Connection Modes by Electrocoagulation. Int J Electrochem Sci 11: 3680-3696.

Parida SK, Dash S, Patel S, Mishra BK (2006) Adsorption of organic molecules on silica surface. Adv Colloid Interfac Sci 121:77-110

O’Neil M J (2013) The Merck Index. An Encyclopedia of Chemicals, Drugs and Biologicals $15^{\text {th }}$ edn. Royal Society of Chemistry, New Jersey.
World Health Organisation (2012) Pharmaceuticals in Drinking Water. Available at https://www.who.int/water_sanitation_health/publi cations/2012/pharmaceuticals/en/.

Punyapalakul P, Sitthisorn T (2010) Removal of ciprofloxacin and carbamazepine by adsorption on functionalised mesoporous silicates. Int J Environ Chem Ecol Geo Geophys Eng 4:412-416

Zhang X, Wu W, Wang J, Tian X (2008) Direct synthesis and characterization of highly ordered functional mesoporous silica thin films with high amino-groups content. Appl Sur Sci 254:2893-2899 